\title{
Análise da Qualidade de Serviços Bancários on-line pelo Computador: Um Estudo sob a Ótica dos Clientes no Papel de Usuários
}

\author{
Tânia Regina Frota Vasconcellos Dias \\ Professora Adjunta \\ Universidade Federal Rural do Rio de Janeiro \\ Rod BR 465, Km 07 \\ 23890-000 - Seropédica-RJ \\ trfvdias@ufrrj.br \\ Marcelo Alvaro da Silva Macedo \\ Doutor em Engenharia da Produção \\ Professor Adjunto \\ Mestrado em Gestão e Estratégia de Negócios da UFRRJ \\ Rod BR 465, Km 07 \\ 23890-000 - Seropédica-RJ \\ malvaro.ufrrj@gmail.com
}

\section{Resumo}

O aumento da competitividade na economia global trouxe para as empresas uma preocupação que consiste em oferecer bens e serviços com qualidade para uma clientela cada vez mais exigente. Tendo em paralelo uma tendência irreversível da crescente industrialização do setor de serviços que cada vez mais utiliza novas tecnologias, principalmente o processamento eletrônico de dados e de telecomunicações, deve-se ampliar a importância deste setor através do desenvolvimento de técnicas de gestão adequadas, não esquecendo da preocupação que se deve ter com a qualidade e produtividade do mesmo para que contribua cada vez mais para melhoria do padrão de vida das pessoas. Esta pesquisa teve como objetivo analisar a qualidade dos serviços bancários on-line pelo computador sob o ponto de vista dos clientes no papel de usuários. Utilizou-se abordagem de aporte do método qualitativo ao quantitativo, com aplicação de questionário aberto aos clientes, em entrevista face a face e questionário fechado construídos com frases-resposta e escala ordinal, tratados com estatística descritiva. A amostra caracterizou-se como de conveniência devido a diversas dificuldades encontradas para uma amostragem aleatória. A pesquisa revela onze fatores de qualidade operacionalizados; e a existência de três grupos de respondentes, formados a partir da aplicação da análise de clusters, que possuíam características similares internamente e diferenças cruciais externas, no que tange ao comportamento em relação às variáveis de pesquisa.

Palavras-chave: Gerência da Qualidade. Banco por Computador. Serviços.

\begin{abstract}
The global economy competivity raise brought to the companies a concern to offer quality goods and services to an each more demanding consumer. Having as a parallel the irreversible tendency of growing industrialization of the services sector that each time more uses new technologies, mainly the electronic data processing and telecommunications, it should extend the importance of this sector through the development of adequate management techniques, not forgetting about the concern it should have with the quality and productivity to contribute each more to enhance peoples living quality. This research had as goal to analyze computer based on-line banking services quality under the point of view of the consumers as users. It
\end{abstract}


was used an approach from the qualitative to the quantitative, with the submission of a open questionnaire to the consumers, with face-to-face interview and closed questionnaire constructed with answers-phrases and ordinal scales, and analyzed with descriptive statistics. The sample was characterized as a convenience one due to the huge difficulties to build a random one. The research reveals eleven operationalysed quality factors; and the existence of three respondents groups, identified from the application of the clusters analysis, which have internal similarities and crucial external differences, in reference to research variables.

Key-words: Quality Management. Computer Banking. Services.

\section{Introdução}

O setor bancário, caracteristicamente de prestação de serviços, é um setor de fundamental importância, tendo em vista o seu papel na Economia. Porém, segundo Crawford (1994), o Sistema Financeiro Mundial está experimentando um redemoinho de mudanças.

Três forças básicas têm gerado essas mudanças - a desregulamentação do setor pela eliminação de antigas leis restritivas, a implementação de nova tecnologia em computadores e as mudanças nos padrões de poupança e endividamento dos consumidores (CRAWFORD, 1994).

Sendo assim, os Bancos são obrigados a se reestruturarem, inovando constantemente, com o oferecimento de bens e serviços que agreguem valor para os seus clientes, retendo-os na empresa pela confiabilidade de seus produtos.

Esta crescente industrialização dos serviços leva os bancos a adoção de processos automatizados, como forma de melhorar seus sistemas operacionais e organizacionais, tornando-se mais ágeis e modernos. Entretanto, de acordo com Sheth et al (2001), o uso desta nova ferramenta, vai estimular mudanças no comportamento do cliente. Este vai cada vez mais assumir o papel de co-produtor, adicionando, na visão de Almeida (1988), nova característica ao processo, que é a participação direta, no mesmo, do cliente, que deixa de ser elemento passivo para se tornar recurso produtivo. Além disso, ressaltam Sheth et al (2001), vai se engajar na desintermediação, transação direta entre produtores e clientes; terceirização, resolver os problemas impostos pelas pressões de tempo, terceirizando o que até agora era produzido em casa e; consumo automatizado.

Neste contexto, o objetivo final do trabalho é analisar a qualidade dos serviços bancários on-line pelo computador do ponto de vista dos clientes, no papel de usuários.

Portanto, o que se busca com esta pesquisa é identificar fatores de qualidade e aspectos prejudiciais; avaliar o grau de importância destes fatores de qualidade e aspectos prejudiciais e verificar a existência de grupos de clientes com a mesma visão sob estas variáveis, gerando um estudo que possa mostrar a visão dos clientes acerca deste serviço, trazendo assim uma contribuição para a busca de sua melhoria contínua.

\section{Gestão de Serviços: Foco no Cliente}

O desenvolvimento da Economia e da sociedade baseada nos conhecimentos é uma economia voltada mais para serviços do que para produtos.

Segundo Grönroos (2003), um serviço é um processo, consistindo em uma série de atividades mais ou menos intangíveis que, normalmente, mas não necessariamente sempre, ocorrem nas interações entre o cliente e os funcionários de serviço e/ou recursos ou bens físicos e/ou sistemas do fornecedor de serviços e que são fornecidas como soluções para problemas do cliente. 
Devido às diversas características das operações de serviço, dentre elas, intangibilidade do produto, a simultaneidade de produção e consumo e heterogeneidade, gerenciar serviços é diferente de gerenciar a produção de bens.

Além disso, a comunicação com o cliente, sendo uma das funções básicas do marketing, tem papel fundamental na formação das expectativas dos consumidores a respeito do serviço a ser prestado.

Desta forma, há necessidade de se garantir coerência entre as estratégias de marketing e operações, visando a prestação de serviços que atendam às expectativas dos consumidores.

Segundo Berry e Parasuraman (1992), o que a empresa faz para criar, alimentar e reforçar o relacionamento com o cliente é decisivo para a eficácia e eficiência de seu marketing. O marketing de relacionamento, de acordo com D'Angelo et al (2006), emergiu, nas últimas duas décadas, como um dos mais promissores campos de investigação do marketing.

O desenvolvimento e solidificação do conceito de marketing de relacionamento e várias das idéias a ele relacionadas, como a existência de um continuum de relacionamento entre a empresa e seus clientes (indo de orientações transacionais até relacionais), trouxeram ainda mais força à identificação e busca de quais fatores explicariam determinados comportamentos dos clientes (BREI e ROSSI, 2005).

Para Zeithaml e Bitner (2003) este representa uma mudança de paradigma para a área de marketing, migrando de um foco em compras/transações para outro em retenção/relações.

Dentre as estratégias de retenção de clientes que a empresa utiliza para promover a lealdade existem quatro níveis: no nível um, laços financeiros, as empresas que fazem o marketing usando incentivos como, preços mais baixos para estimular os clientes a trazer mais negócios para a empresa.

O nível dois, empresas que fazem o marketing formando elos sociais acima dos elos financeiros, dá ênfase à prestação de serviço personalizada e a transformação de consumidores em clientes.

O nível três, laços de customização, compreende mais que laços sociais e incentivos financeiros, havendo elementos comuns com as duas estratégias anteriores. É a fidelização de clientes através de estímulo de conhecimento íntimo enquanto indivíduos e pelo desenvolvimento de soluções "um a um", que atendam as necessidades individuais dos clientes.

O nível quatro consolida os relacionamentos com elos estruturais, além dos elos sociais, financeiros e de individualização entre cliente e empresa. São serviços em geral, que têm base na tecnologia e visam a ajudar os clientes a se tornarem mais eficientes e produtivos. O principal objetivo neste nível é proporcionar serviços que acrescentem valor.

\section{Valor de Mercado para o Cliente}

Segundo Brei e Rossi (2005) valor é definido pelos consumidores como a utilidade de um produto ou serviço baseado em suas percepções da diferença entre os benefícios e os custos de manutenção de um relacionamento contínuo com seu provedor. Para Sheth et al (2001) é o que os clientes buscam nos produtos, serviços ou fornecedores.

A orientação para o cliente (também conhecida como orientação para o mercado) segundo Kohli e Jaworski (1990) citados em Sheth et al (2001), significa pleno entendimento dos desejos e necessidades dos clientes, do ambiente competitivo e da natureza do mercado, empregado para formular todos os planos e ações da empresa a fim de criar clientes satisfeitos.

De acordo com Slongo e Müssnich (2005) a oferta de produtos e serviços, como todos os elementos numa experiência de consumo, são destinados a propiciar valor para os clientes. 
Para Sheth et al (2001), o reconhecimento dos clientes como pessoas que buscam soluções para problemas e do valor que os mesmos buscam de um produto ou serviço podem ser classificados como, valores universais e valores pessoais.

Os primeiros estão relacionados ao propósito básico (necessidades), condição física insatisfatória do cliente que o leva a uma ação que irá satisfazer ou sanar essa condição. Leva alguém a comprar um produto ou serviço ou a fazer negócio com uma empresa. São a base das estratégias de diferenciação de produtos.

Já os valores pessoais, são relacionados aos desejos do cliente, condição psicológica/social insatisfatória do cliente que o leva a uma ação que irá satisfazer ou sanar essa condição, portanto, diferindo de pessoa para pessoa. Se desejados por um segmento ou grupo de clientes são específicos de grupo e servem de base para as estratégias de segmentação. Quando estes valores são individualizados, específicos de indivíduos, servem de estratégia para o marketing de relacionamento.

As necessidades e desejos também diferem em termos dos fatores que os causam. As necessidades são determinadas pelas características do indivíduo e do ambiente, em contrapartida, os desejos são determinados pelo contexto individual e ambiental.

Os valores possuem características. São instrumentais, pelo fato de os produtos e serviços serem instrumentos para satisfazer as necessidades e desejos dos clientes. São dinâmicos, quando os clientes mudam em seu estágio de vida, em seus recursos, ou de expectativas que surgem em todo mercado. E são hierárquicos, os valores universais são valores de mercado que um produto ou serviço deve oferecer em primeiro lugar.

A diversidade dos valores dos clientes, aumenta com a hierarquia. Os valores também são sinérgicos, um valor aumenta a utilidade de outro valor; e, os valores variam de um cliente para outro.

Os clientes assumem três tipos de papéis para o mercado: Usuário, Pagante e Comprador e buscam os seguintes valores no mercado (SHETH et al, 2001):

- Para os usuários, o valor universal é o desempenho, ou seja, a qualidade do resultado físico de sua utilização. O valor pessoal de grupo é o social, quando um produto passa a ser associado com grupos sociais que causam uma percepção positiva; e valor pessoal individual é o emocional; serviço que está sendo oferecido sob medida, ligado ao conteúdo do produto, prazer e a satisfação emocional que produtos ou serviços oferecem aos seus usuários. Ambos se relacionam aos benefícios sociais que trazem.

- Para os pagantes, o valor universal é o preço, ou seja, os preços e outros custos financeiros em que se incorre ao adquirir um produto considerando as compensações que receberão. O valor pessoal é o crédito no nível de grupo, é um valor de "conveniência" ao fazer o pagamento, geralmente para um grupo de clientes qualificados; e o financiamento no nível individual, é um arranjo de crédito com grau maior de personalização. Estes consistem em facilitar para o cliente o pagamento ao produto ou serviço.

- Para os compradores, o valor universal é o de serviço, o atendimento que os clientes buscam ao adquirirem um produto ou serviço. $\mathrm{O}$ valor pessoal é a conveniência, ao nível de grupo, refere-se a economizar o tempo e o esforço necessário para adquirir o produto. E o pessoal ao nível individual é a personalização, a compra (negociação) de modo personalizado ou individualizado.

O valor só é criado se o produto ou serviço tem a capacidade de satisfazer às necessidades e desejos de um cliente. A essa satisfação denominamos oferta de valor.

A oferta de valor é composta por duas dimensões: a eficácia, quando um produto se torna capaz de satisfazer a necessidade ou um desejo do cliente e, a eficiência, quando há um 
custo mínimo para o cliente, medido em dinheiro, tempo ou esforço físico para receber esse valor.

Quando estas duas dimensões, eficácia e a eficiência, estão sendo bem articuladas podemos dizer que a empresa está oferecendo o melhor valor para o cliente. Além disso, o contexto ou situação do cliente pode conferir maior ou menor valor a um produto ou serviço.

\section{Serviços Bancários e o Atendimento por Computador}

Segundo Salinas (1993), existem três características da qualidade de serviços bancários: o atendimento bancário com qualidade, que se caracteriza por apresentar agilidade e respostas rápidas às solicitações e necessidades dos clientes; comunicação e informatização, em que a satisfação dos clientes se concretiza através de respostas rápidas, ágeis e seguras para suas exigências, necessidades e problemas; e operações, cuja qualidade, se traduz na disponibilidade de produtos e serviços adequados as necessidades dos clientes, ínfimo nível de erros, baixíssimo nível de burocratização e, principalmente no pessoal qualificado, capaz de resolver problemas e dirimir dúvidas.

O processo de automação bancária apresenta três dimensões (FALCÃO, 1993):

- Processamento Eletrônico de Dados em nível de retaguarda, através da adoção de um Centro de Processamento de Dados (CPD) central, que é responsável pela consolidação e geração de banco de dados referentes a todas as operações conduzidas pela instituição;

- Sistemas de apoio à decisão, com o intuito de auxiliar a tomada de decisões em nível de gerência e da alta administração, e;

- Automação de atividades de atendimento junto ao público.

Este conceito constitui a base de incontáveis inovações desde simples equipamentos utilizados nas agências até modelos mais sofisticados, como é o caso do banco doméstico Home Banking.

Segundo Dias (1998) na década de 90, os serviços de atendimento por telefone, computador ou fax espalharam-se pelo sistema. No Brasil do Real, essa nova tendência no atendimento bancário, tende a ampliar não só automação dos seus serviços, proliferando cada vez mais os caixas automáticos, como facilitar a compra de computadores, financiando-os, de maneira a incentivar o contato com o cliente em sua casa, ou escritório, formando uma rede que facilitará a proliferação das transações eletrônicas.

Com isso, pode-se dizer que os serviços bancários possuem as seguintes características quanto ao atendimento ao cliente:

- Atendimento face a face: este tipo de atendimento caracteriza-se por um contexto onde o cliente tem uma grande interação, se envolvendo direta e ativamente no processo da prestação de serviços. Dentro deste contexto a interação se dá muito mais com fatores de ambiente físico, como os aspectos ambientais e de projeto da agência, bem como os fatores sociais, que são as pessoas do ambiente, os funcionários e outros clientes. A heterogeneidade é uma característica marcante nesta modalidade, devido a presença de fatores sociais na interação.

- Atendimento em Serviços on line: são serviços automatizados em que o cliente pode acessar uma agência bancária para realizar transações financeiras dentro ou fora do seu horário de atendimento, através de caixas automáticas, de quiosques eletrônicos, ou mesmo de sua residência ou escritório, através do telefone ou do computador. Estes resultam de um novo relacionamento BANCO/CLIENTE, com o objetivo de abrir um novo canal de comunicação, possibilitando a prestação de serviço à distância - "Home-Banking”. 
- Banco por Computador: é uma modalidade de serviços on line, onde o cliente tem a comodidade, distanciando-se das filas, e com economia de tempo, de acessar o banco diretamente de sua residência ou escritório, através de computadores. Neste tipo de serviço automatizado, observa-se que, fatores ligados ao ambiente físico inexiste ou são de pouca intensidade, havendo uma interação mínima do cliente com os funcionários do banco, pois na maioria das vezes o cliente acessa sozinho o serviço, tornando a prestação do mesmo impessoal. Pode-se dizer que inexiste a heterogeneidade como característica desta prestação de serviços. (DIAS e MACEDO, 2003)

A nova tecnologia da informação está proporcionando as empresas uma melhor compreensão das necessidades dos seus clientes e o uso da internet é visto cada vez mais como uma ferramenta para criar valor.

A flexibilidade da Internet permite que uma empresa execute sua estratégia de criar valor para o cliente, quando através dela oferece mais um meio para exibir produtos e serviços e prestar tantas informações quantas os clientes desejarem; oferecer melhor atendimento e preço; posicionar-se como concorrente de menor custo, quando não precisa financiar as instalações físicas. Outro fator importante é a conveniência de localização, facilidade de uso e disponibilidade, pois torna muito mais fácil, para os clientes, algumas tarefas envolvidas com as compras de serviço e/ou produtos.

\section{Metodologia}

Para este trabalho adotou-se um modelo de pesquisa, proposto por Dias (1998), em que os fatores de qualidade foram estudados em associação com os aspectos prejudiciais, visando contemplar ambos, na elaboração dos fatores de qualidade operacionalizados, contribuindo desta forma para a avaliação da qualidade de serviços bancários on-line pelo computador.

O problema proposto para investigação é de natureza descritiva, caracterizando-se o seu estudo, como estudo descritivo, ao procurar identificar fatores de qualidade e operacionalizá-los contemplando os aspectos favoráveis e desfavoráveis a seu julgamento. A especificação de informação a ser contemplada no instrumento de coleta de dados e a identificação de frases-resposta foi realizada através da revisão bibliográfica. A abordagem, de aporte do método qualitativo ao quantitativo foi utilizada por opção nesta pesquisa.

A coleta de dados foi realizada através de entrevista face a face, num primeiro momento, aplicada a trinta e oito entrevistados, no período de março a junho de 2003 . Num segundo momento, mediante roteiros estruturados e questionário fechado auto-aplicável, enviado pelo correio, foi composta por duzentos e cinqüenta respondentes escolhidos por conveniência dos pesquisadores, dos quais oitenta e seis foram aproveitados na análise. Os dados desta segunda parte foram obtidos no período de novembro de 2003 a junho de 2004.

Para o tratamento de dados das entrevistas utilizou-se a análise de conteúdo com categorização a posteriori. $\mathrm{Na}$ análise dos questionários fechados, construídos com frases respostas e escala ordinal, foi utilizado tratamento estatístico mediante a utilização de análises univariada e multivariada.

A população da pesquisa constitui-se de clientes de serviços bancários on-line pelo computador do Estado do Rio de Janeiro. A amostra caracterizou-se como de conveniência devido às diversas dificuldades encontradas para uma amostragem aleatória, como por exemplo, identificar todos os clientes do sistema on-line pelo computador residentes no Estado do Rio de Janeiro e sorteá-los com a mesma chance de serem escolhidos. 
Neste caso optou-se por abordagem aos clientes desta prestação de serviços que porventura estejam realizando algum contato pessoal com agências bancárias localizadas no Estado do Rio de Janeiro. Por conta disso, esta pesquisa apresenta como limitação o fato de que suas conclusões não podem ser usadas para fazer inferências a respeito da população.

Para a consecução da pesquisa foi necessário traçar os seguintes passos metodológicos:

- Na Análise Qualitativa:

- Identificar os fatores de qualidade e os aspectos prejudiciais do ponto de vista dos clientes, quanto à qualidade dos serviços bancários on-line pelo computador;

- Operacionalizar os fatores de qualidade do ponto de vista dos clientes, quanto à qualidade dos serviços bancários on-line pelo computador.

- Na Análise Qualitativa:

- Avaliar o grau de importância dos fatores de qualidade e dos aspectos prejudiciais quanto à qualidade dos serviços bancários on-line pelo computador.

- Verificar a existência de grupos de clientes com a mesma visão sob estas variáveis.

\section{Apresentação e Análise dos Resultados da Pesquisa}

\subsection{Análise Qualitativa}

Visando a identificação dos Fatores de Qualidade e dos Aspectos Prejudiciais utilizouse como instrumento de coleta de dados um questionário aberto, composto de 3 (três) perguntas em que, os clientes pudessem expressar suas opiniões "Na sua opinião, o que é serviço bancário de boa qualidade pelo computador?", "O que ocorre que prejudica a qualidade do serviço prestado? (caso haja algum problema)”, "Quais são as vantagens $e$ desvantagens desse tipo de serviço?"

As perguntas foram formuladas de maneira a obter não somente dados sobre atributos-chave da qualidade, ou seja, fatores de qualidade, como também aspectos prejudiciais, visando obter subsídios para o gerenciamento da qualidade.

Este questionário foi aplicado junto a trinta e oito clientes do sistema bancário on-line pelo computador, para identificar o que eles percebem como sendo atributos-chave desta qualidade de prestação de serviços.

Ao analisar as respostas fornecidas à terceira pergunta, “Quais são as vantagens $\boldsymbol{e}$ desvantagens desse tipo de serviço?" alguns usuários deixaram de responder alegando estar satisfeitos com este tipo de serviço, e só viam vantagens no serviço, como podemos mostrar em algumas frases citadas abaixo:

- "Não vejo desvantagem nenhuma, contanto que nenhum hacker descubra senha e faça o estrago na minha conta".

- "Se o serviço for de boa qualidade, não vejo desvantagens".

- "Não há desvantagens, só vantagens".

- "Este tipo de serviço só traz vantagens".

\subsubsection{Identificação de Fatores de Qualidade:}

Para identificar os fatores de qualidade propôs-se a questão aberta: "Na sua opinião, o que é serviço bancário de boa qualidade pelo computador?", o que permitiu formular doze categorias para os fatores de qualidade: 
"Rapidez na obtenção das informações e transações dos serviços"; "Simplicidade no processo para efetuar operações, serviço bem explicado"; "Segurança e sigilo nas informações e transações durante as operações bancárias"; "Possibilidade de acesso rápido às informações a partir de qualquer lugar e horário"; "Clareza e exatidão das informações"; "Possibilidade de realizar todas as informações e transações que necessito"; "Disponibilizar todos os produtos do banco"; "Baixo custo das operações"; "Facilidade de manter-se atualizado(a) sobre movimento bancário" e "Imagem do banco virtual".

As categorias: "O fato de não ser necessário deslocar-se a agência" $e$ "Impessoalidade", não foram consideradas como fatores de qualidade, por constituírem-se na própria característica do serviço. A primeira, por ser a garantia do próprio mercado para a oferta do serviço, configurando-o como opção de negócio, a comodidade de poder obter as informações e resolver os problemas pelo computador sem precisar ir ao banco; e a segunda, como uma consequiência, pois o fato de não ter que se deslocar até a agência e poder resolver tudo por computador sem ter que ver ou falar com ninguém traz impessoalidade a esta prestação de serviço.

\subsubsection{Identificação de Aspectos Prejudiciais:}

Para identificar os aspectos prejudiciais propôs-se a questão aberta "O que ocorre que prejudica a qualidade do serviço prestado? (caso haja algum problema)", o que permitiu formular onze categorias para os aspectos prejudiciais:

"Falta de segurança por parte dos sistemas disponíveis durante as transações"; "Dificuldade de acesso ao site do banco pelo computador"; "Demora para realizar as transações impedindo que a operação se concretize"; "Sistema de operação com falta de informações e instruções pouco claras"; "Informações incompletas e serviços realizados de forma incorreta"; "Falta de personalização na prestação do serviço"; "Responsabilidade do banco é menor no caso de erro quando o atendimento é on-line"; "Multiplicidade de senha para memorização"; "Despesas com a operação do serviço" e "Falta de Credibilidade".

A categoria, "Não permitir depósitos" foi excluída desta relação por entender que a mesma constitui-se numa limitação desta prestação de serviço.

\subsubsection{Operacionalização dos Fatores de Qualidade e dos Aspectos Prejudiciais:}

Para a consecução do segundo passo metodológico foram necessárias três etapas: contraposição entre os fatores de qualidade e os aspectos prejudiciais; análise da contraposição entre os fatores de qualidade e os aspectos prejudiciais; e criação de artifícios para nova contraposição entre fatores de qualidade e aspectos prejudiciais.

Com a finalidade de melhorar a compreensão dos Fatores de Qualidade do ponto de vista dos clientes de serviços bancários on-line pelo computador procedeu-se a uma contraposição dos mesmos, com os aspectos que podem prejudicar o seu gerenciamento (Quadro 01).

Conforme exposto no item anterior, "O fato de não ser necessário deslocar-se a agência" e "Impessoalidade" por constituírem-se em características do serviço; e "Não permitir depósitos" constituir-se numa limitação, não serão tratadas como fatores de qualidade e como aspecto prejudicial, respectivamente, cujo gerenciamento permite obter uma melhor qualidade do serviço.

Observou-se que dos dez aspectos prejudiciais, apenas nove deles fizeram contraposição aos fatores de qualidade:

a) "Demora em realizar as transações impedindo que a operação se concretize", devido ao sistema está sobrecarregado, congestionamento de linhas, a conexão lenta, constituem-se em aspectos prejudiciais à rapidez tão esperada pelo cliente na obtenção 
de suas informações e transações dos serviços. O que contribui para a percepção negativa da qualidade deste serviço.

b) "Sistema de operação com falta de informações e instruções pouco claras" comprometem a qualidade do serviço durante a execução do mesmo, pois o cliente espera "Simplicidade no processo para efetuar suas operações, e que o serviço seja bem explicado".

c) "Falta de segurança por parte dos sistemas disponíveis durante as transações" devido a ação de hackers, clonagem constitui um aspecto negativo a "Segurança e sigilo nas informações e transações durante as operações bancárias", bem como a "Multiplicidade de senha para memorização" traz dificuldades prejudicando o acesso correto as transações do cliente trazendo insegurança para as operações dos mesmos.

d) "Dificuldade de acesso ao site do banco pelo computador" devido a sistema fora do ar, falta de conexão prejudica a qualidade no atendimento on-line trazendo pouca disponibilidades para o acesso rápido às informações a partir de qualquer lugar e horário.

e) "Informações incompletas e serviços realizados de forma incorreta", contrapõe a "Clareza e exatidão das informações" tão requerida pelos clientes, pois falta de confiabilidade ao serviço induzem a um julgamento negativo da qualidade quando o cliente precisa efetuar suas operações.

f) "Falta de Credibilidade" cria um aspecto prejudicial a realização de todas as informações e transações que o cliente necessita, induzindo a um julgamento negativo do serviço quando o cliente não consegue resolver todos os seus problemas. Tanto a eficiência, quanto a eficácia ficam comprometidas.

g) "Despesas com a operação do serviço" através das cobranças de tarifas e conta telefônica alta é uma contraposição a "Baixo custo das operações", visto que as despesas altas poderão interferir na compra desta modalidade de prestação de serviço. $\mathrm{O}$ cliente quer pagar menos imposto ou não quer pagar pelo extrato.

h) "Responsabilidade do banco é menor no caso de erro, quando o atendimento é online". Este aspecto prejudicial contrapõe a "imagem do banco virtual" reforçando um marketing boca a boca negativo quando o mesmo não leva em consideração problemas que possam ocorrer com o cliente durante o processo, como alguns aspectos prejudiciais já citados anteriormente.

Em dois dos fatores de qualidade: "Disponibilizar todos os produtos do banco" e "Facilidade de manter-se atualizado(a) sobre movimentos bancários", a amostra não menciona aspectos prejudiciais que possam a princípio ser considerados como contrapostos. Provavelmente, os mesmos não foram entendidos como de suma importância no julgamento da qualidade do serviço prestado e por esse motivo não foram expressos os aspectos prejudiciais, ou ainda talvez em sua vivência não tenha se deparado com este problema.

Para aumentar o poder de análise com o objetivo de entender melhor os aspectos que possam vir a prejudicar a avaliação desta prestação de serviço, como nos mostra o (quadro 01), optou-se pela criação de artifícios (itálico e negrito), descrito a seguir (quadro 02). Foram criados os seguintes artifícios como aspectos prejudiciais: "Não disponibilizar todos os produtos do banco"; e "Dificuldade de manter-se atualizado sobre movimento bancário". $\mathrm{O}$ primeiro por não cobrir uma oferta maior de produtos e serviços aos clientes; o segundo por inviabilizar a continuidade do atendimento ao cliente.

Note-se que, um outro artifício foi criado: "Personalização”, como fator de qualidade, em contraposição ao aspecto prejudicial, "Falta de personalização na prestação de serviço", indicando a atenção que o cliente deseja receber para resolver os problemas, que possam aparecer durante o processo de atendimento nesta prestação do serviço. 
Com a contraposição dos Fatores de Qualidade e dos Aspectos Prejudiciais e com a criação dos artifícios (quadro 01 - anexos), foi possível finalmente generalizar os Fatores de Qualidade. (quadro 02 - anexos)

Note-se que, ao levantar os aspectos prejudiciais, torna-se necessário operacionalizar os fatores de qualidade, apresentando o que pode prejudicá-los tendo em vista ser a qualidade de serviços julgada do ponto de vista do cliente, optou-se pela operacionalização dos fatores a partir da sua percepção.

\subsection{Análise Quantitativa}

A questão da relevância dos fatores de qualidade é de suma importância tanto para a elaboração de um sistema de avaliação da qualidade dos serviços, quanto para direcionar as estratégias de marketing. Assim sendo, esta parte da pesquisa procura identificar junto aos clientes qual a importância de cada um dos fatores de qualidade e aspectos prejudiciais identificados e operacionalizados anteriormente.

De posse dos resultados da análise desta parte exploratória da pesquisa, montou-se o questionário com perguntas fechadas formado pelos doze fatores de qualidade e os onze aspectos prejudiciais segundo o julgamento do cliente, onde foi pedido ao respondente que enumerasse por ordem de importância. A amostra acidental foi formada por oitenta e seis clientes de serviços bancários on-line pelo computador, sendo 39 pessoas do sexo masculino e 47 do sexo feminino. As características demográficas com ao sexo, à escolaridade, à idade e à renda familiar, estão nos gráficos nos anexos.

\subsubsection{Avaliação do Grau de Importância do Fatores de Qualidade Operacionalizados}

Tomando por base medidas de tendência central e frequiências relativas dos fatores de qualidade e dos aspectos prejudiciais, os mesmos apresentaram novos posicionamentos, desta forma foi possível levantar a importância dos Fatores de Qualidade Operacionalizados, quanto á amostra e a importância dos Fatores de Qualidade Operacionalizados, segundo abordagem qualitativa e quantitativa (quadro 03 - anexos).

Quanto aos fatores de qualidade: as variáveis (V8) "Impessoalidade" e (V10) "O fato de não ser necessário deslocar-se a agência" foram retiradas por serem consideradas características desta prestação de serviço. Quanto aos aspectos prejudiciais: a variável (V20) Não permitir depósitos foi retirada por ser considerada uma limitação.

Percebe-se na análise destes resultados que:

- Efetivar comunicações rápidas é primordial para o cliente deste serviço. Portanto, grande importância deve ser dada pelas áreas de operações e marketing no gerenciamento da qualidade deste fator, compartilhando um relacionamento no nível quatro, relacionamentos com elos estruturais, além dos elos sociais, financeiros e de individualização entre cliente e empresa, visando a ajudar os clientes a se tornarem mais eficientes e produtivos, proporcionando serviços que acrescentem valor;

- O Acesso às informações é um atributo relacionado a comodidade, que indica a importância da parceria do banco com provedores de prestação de serviços de Internet;

- O cliente deseja realizar todas as suas operações com credibilidade;

- Os clientes querem sentir segurança durante as transações e sigilo bancário, o que reforça a importância do relacionamento principalmente com a área de marketing quando da comunicação da imagem do banco, quanto a solidez, a honestidade e o valor do serviço;

- Há necessidade de melhorar a oferta de serviço a baixo custo; 
- É importante obter não só a comodidade, quando da opção por este tipo de prestação de serviço, bem como facilidade de efetuar as operações dada a impessoalidade. Daí resultada uma parceria com responsabilidade compartilhada entre as áreas de desenvolvimento de produto e de processo.

\subsubsection{Análise de Formação de Grupos de Respondentes}

Com as respostas obtidas dos respondentes pertencentes a esta amostra foi possível identificar grupos de respondentes que tivessem características similares dado suas posturas frente às características de qualidade e aspectos prejudiciais dos serviços bancários on-line pelo computador. Desta forma foi necessária a utilização da Análise de Clusters ou Conglomerados, através da aplicação do software SPSS 9.0 da SPSS Inc.

A Análise de Cluster é, segundo Hair et al (2005), uma técnica analítica que pode ser usada para definir grupos significativos de respondentes e/ou de variáveis. Um de seus objetivos específicos é agrupar os que possuam características similares, em função das respostas obtidas. Com isso consegue-se identificar grupos que se comportam internamente de maneira uniforme e externamente de maneira diferentes, e variáveis que melhor explicam esta discriminação.

Um outro objetivo específico é classificar uma amostra de muitas variáveis em um número pequeno de grupos (fatores) mutuamente exclusivos baseados nas similaridades entre as variáveis da amostra. Com a aplicação dessa técnica, o pesquisador reduz o número de variáveis a trabalhar, estudando um pequeno número de grupos de variáveis com características semelhantes, ou seja, os fatores, com o mínimo de perda de precisão das informações originais.

De acordo com Mattar (1998) a análise de conglomerados permite ao pesquisador classificar objetivos ou indivíduos observados em relação a inúmeras variáveis em subgrupos ou conglomerados não definidos a priori, mas que surgem em função da análise realizada.

Para Malhotra (2001) a Análise de Conglomerados é uma técnica usada para classificar objetos (variáveis ou respondentes) em grupos relativamente homogêneos. Os objetos, em cada conglomerado, tendem a serem semelhantes entre si, mas diferentes de objetos em outros grupos. $\mathrm{Na}$ análise de conglomerados não há qualquer informação a priori sobre a composição do grupo para qualquer de seus objetos, e na verdade é definida pelas próprias características dos dados.

Na aplicação da análise de conglomerados aos dados desta pesquisa, com o objetivo de formar grupos de respondentes, obtiveram-se três grupos, os mesmos apresentam características com relação as variáveis dos fatores de qualidade e dos aspectos prejudiciais, quanto a sexo, idade, escolaridade, conforme discriminado a seguir:

GRUPO 01 - Rapidez e Comodidade com Segurança (grupo possui 25 mulheres e 16 homens, e apresenta características intermediárias tanto com relação a escolaridade, idade e renda)

GRUPO 02 - Segurança e Credibilidade (grupo possui 22 mulheres e 17 homens, e tem a renda mais alta e a maior média de idade)

GRUPO 03 - Serviço diversificado, Personalizado e Rápido (grupo possui 6 homens e tem a maior escolaridade, a menor renda e a menor média de idade)

O Quadro 04, nos anexos, mostra os resultados com as variáveis relevantes na identificação dos Grupos de respondentes. Na análise deste quadro, observa-se que o Grupo 01 tem como característica Rapidez e Comodidade com Segurança, pois consideraram como mais valorizados três dos fatores de qualidade: as variáveis (V9) Possibilidade de acesso rápido as informações a partir de qualquer lugar e horário, (V1) Rapidez na obtenção das informações e transações dos serviços e (V10) O fato de não ser necessário deslocar-se a agência, denotando duas características importantes: a rapidez e a comodidade. Nota-se que 
neste grupo, quanto aos aspectos prejudiciais, os mais importantes são (V19) Falta de segurança por parte dos sistemas disponíveis durante as transações e (V20) Não permitir depósitos, denotando uma insatisfação quanto à segurança e a comodidade.

O Grupo 02 tem como característica Segurança e Credibilidade, pois prioriza como fator de qualidade, a variável (V7) Segurança e sigilo nas informações e transações durante as operações bancárias e, considera como aspectos mais prejudiciais, (V19) Falta de segurança por parte dos sistemas disponíveis durante as transações e (V15) Falta de credibilidade, já que esta pode ser entendida como correlacionada a fatores de segurança.

O Grupo 03 é caracterizado como o grupo do Serviço diversificado, Rápido e Personalizado, pois valoriza como fatores de qualidade as variáveis (V4) Disponibilizar todos os produtos do banco, (V3) Possibilidade de realizar todas as informações e transações que necessita e (V1) Rapidez na obtenção das informações e transações dos serviços, e por considerar como um dos fatores mais prejudiciais ao serviço a variável (V23) Demora em realizar as transações impedindo que a operação se concretize. Sendo assim, reforça duas de suas três características: serviço diversificado e rápido. A terceira característica deste grupo, personalizado, fica evidente quando da escolha das variáveis (V20) Não permitir depósitos e (V21) Falta de personalização na prestação de serviço, como as mais prejudiciais.

Em consonância com esta análise, percebe-se que os grupos 01 e 02 se diferenciam basicamente pela insensibilidade dos respondentes do grupo 02 com relação a comodidade e pela quase "irracional" preocupação com a questão de segurança (V19). Mas estes grupos concordam entre si quando escolhe a variável (V8) Impessoalidade, como menos valorizada.

Para os grupos 01 e 03, percebe-se que a única questão que os aproxima é a rapidez (variável V1), pois existe uma grande diferença entre eles quanto a comodidade desta prestação de serviço. Isto pode ser visto numa análise da variável (V10) O fato de não ser necessário deslocar-se a agência. Enquanto o grupo 01 considera este um dos fatores de qualidade mais valorizados, o grupo 03, a considera na lista dos menos valorizados.

Ao analisar os três grupos, numa maneira geral, percebe-se uma questão importante que os diferenciam: o fato de que, como dito anteriormente, o grupo 03 é o único que não tem na segurança uma preocupação latente.

\section{Conclusão}

A partir da análise dos resultados no contexto desta prestação de serviço conclui-se:

- "Rapidez na obtenção das informações e transações dos serviços", foi considerado o fator de qualidade mais importante.

- Os Fatores de qualidade operacionalizados mais importantes para o gerenciamento da qualidade desses serviços e conseqüentemente para a avaliação da performance dos mesmos, pois totalizam (70\%) das respostas obtidas são: "Rapidez na obtenção das informações e transações dos serviços", "Segurança e sigilo nas informações e transações durante as operações bancárias", "Possibilidade de acesso rápido às informações a partir de qualquer lugar e horário", "Simplicidade no processo para efetuar operações; serviço bem explicado", "Clareza e exatidão das informações", "Possibilidade de realizar todas as informações e transações que necessito".

- Quanto aos Aspectos Prejudiciais: "Falta de segurança por parte dos sistemas disponíveis durante as transações", "Dificuldade de acesso ao site do banco pelo computador" e "Demora em realizar as transações impedindo que a operação se concretize", absorveram 70,77\%, da totalidade das respostas, chamando atenção da gerência, para uma melhor administração das mesmas, pois a qualidade deste serviço poderá ficar afetada se o cliente não obtiver acesso rápido e fácil as informações e transações com segurança. 
A rapidez na obtenção das informações e transações dos serviços (V1) é um fator de qualidade que foi tido como relevante por dois dos três grupos (01 e 03). Já a imagem do banco virtual (V12) foi tida como uma das menos importantes para os três grupos, denotando indiferença pela marca do banco. A falta de segurança por parte dos sistemas disponíveis durante as transações (V19) e o fato de não permitir depósitos (V20) foram tidos como aspectos prejudiciais entre os mais relevantes em dois dos três grupos (01 e 03). A impessoalidade (V8) é a menos valorizada pelos grupos (01 e 02) e para o grupo 03 é indiferente, por considerar menos valorizado o fato de não ser necessário deslocar-se a agência.

$\mathrm{Na}$ análise para formação dos grupos algumas variáveis se apresentaram como cruciais. Este é o caso dos fatores de qualidade segurança e sigilo nas informações e transações durante as operações bancárias (V7) e o fato de não ser necessário deslocar-se a agência (V10) e dos aspectos prejudiciais não permitir depósitos (V20), falta de personalização na prestação do serviço (V21) e falta de credibilidade (V15). Através de uma análise do comportamento dos respondentes em relação a cada uma dessas variáveis pode-se perceber a formação dos diversos grupos apontados anteriormente.

A segurança e sigilo nas informações e transações durante as operações bancárias (V7) é tida como importante apenas para o grupo 02 e $\mathrm{O}$ fato de não ser necessário deslocar-se a agência (V10), tida como uma das mais importantes para o grupo $01 \mathrm{e}$, como uma das menos importantes para o grupo 03.

Não permitir depósitos (V20) é um dos aspectos prejudiciais mais importantes para os grupos 01 e 03 e ao mesmo tempo um dos menos relevantes para o grupo 02. A falta de personalização na prestação do serviço (V21) é tida como uma das menos importantes para os grupos 01 e 02 e como uma das mais relevantes para o grupo 03. Já a falta de credibilidade é importante para o grupo 02 e não tem importância alguma para os grupos 01 e 03 .

Nos resultados desta pesquisa observou-se que o sucesso deste serviço deve-se ao fato de os clientes estarem dispostos a dispensar o contato pessoal com o banco para obter a conveniência, comodidade que a automação oferece, mas o impacto negativo da falta de personalização, e dos fatores ligados a segurança e a rapidez poderão trazer maiores problemas para a qualidade na prestação de serviços.

Para que os bancos possam conhecer profundamente os seus clientes, os gerentes de marketing e operações devem trabalhar um relacionamento com os clientes no nível quatro, elos estruturais, visando ajudar os clientes a se tornarem mais eficientes e produtivos, associando as ofertas às necessidades e desejos específicos dos clientes, consolidando os relacionamentos além dos elos sociais, financeiros e de individualização entre cliente e empresa, proporcionando serviços que acrescentem valor, refletindo o benefício total que os clientes recebem pelo total de custo que incorrem.

Sendo serviço de natureza intangível, o mesmo deverá ser bem administrado, pois serviço é o produto fundamental, é o diferencial entre as empresas; o sucesso dependerá da forma como estas, "criam valor para o cliente".

Assim, quando um cliente compra um serviço por computador, na realidade ele não está só comprando um serviço que lhe proporcione comodidade e rapidez das transações com segurança, mas também que lhe proporcione benefícios pessoais (social e emocional).

\section{Referências}

ALMEIDA, I. M. P. O Comportamento de Grandes Empresas Brasileiras face a Automação Bancária. 1988. 190 f. Dissertação (Mestrado em Administração) - COPPEAD, Universidade Federal do Rio de Janeiro, Rio de Janeiro. 
D’ANGELO, A. C.; SCHNEIDER, H.; LARÁN, J. A. Marketing de Relacionamento junto a Consumidores Finais: um estudo exploratório com grandes empresas brasileiras. Revista de Administração Contemporânea, Rio de Janeiro, v.10, n. 1, p. 73-93, 2006.

BERRY, L. L.; PARASURAMAN, A. Serviços de Marketing: competindo através da qualidade. São Paulo: Maltese-Norma, 1992. 238 p.

BREI, V. A.; ROSSI, C. A. V. Confiança, Valor Percebido e Lealdade em Trocas Relacionais de Serviço: um estudo com usuários de Internet Banking no Brasil. Revista de Administração Contemporânea, Rio de Janeiro, v. 9, n. 2, p. 145-168, 2005.

CRAWFORD, R. Na Era do capital Humano. São Paulo: Atlas, 1994. 186 p.

DIAS, T. R. F. V. Qualidade de Serviços Bancários on-line pelo Telefone: contribuição para uma metodologia de avaliação. 1998. 187 f. Dissertação (Mestrado em Administração) - Universidade Federal Fluminense, Niterói.

DIAS, T. R. F. V.; MACEDO, M. A. S. Qualidade de Serviços Bancários por Computador: uma visão da oferta de valor. In: SIMPÓSIO DE GESTÃO E ESTRATÉGIA DE NEGÓCIOS DA UFRuralRJ, 1, 2003, Seropédica. Anais do I SIMGEN. Seropédica: PPGEN/NEGEN/UFRuralRJ, 2003. 1 CD.

FALCÃO, R. M. B. R. Comportamento do Consumidor diante da Automação Bancária: um estudo entre universitários. 1993. 140 f. Dissertação (Mestrado em Administração) COPPEAD, Universidade Federal do Rio de Janeiro, Rio de Janeiro.

GRÖNROOS, C. Marketing: gerenciamento e serviços. 2 ed. Rio de Janeiro: Elsevier, 2003. $482 \mathrm{p}$.

HAIR, J. F.; ANDERSON, R. E.; TATHAM, R. L.; BLACK, W. C. Análise Multivariada de Dados. 5 ed. Porto Alegre: Bookman, 2005. 745 p.

KOHLI, A. K.; JAWORSKI, B. J. Marketing orientation: the construct, research propositions ans managerial implications. Journal of Marketing, v. 54, n. 3, 1990. In: SHETH, J. N.; MITTAL, B. e NEWMAN, B. I. Comportamento do cliente: indo além do comportamento do consumidor. São Paulo: Atlas, 2001. 795p.

MALHOTRA, N. K. Pesquisa de Marketing: uma orientação aplicada. 3 ed. Porto Alegre: Bookman, 2001. 719p.

MATTAR, F. N. Pesquisa de Marketing. 2 ed. v. 02. São Paulo: Atlas, 1998. 224 p.

SALINAS, J. L. A Gestão da Qualidade nas Indústrias de Serviços Financeiros: proposta de uma metodologia de implantação na área bancária. In: ENCONTRO NACIONAL DE PÓSGRADUAÇÃO EM ADMINISTRAÇÃO, 27, 1993, Salvador. Anais do XVII ENANPAD. Salvador, ANPAD, 1993. p. 124-137.

SHETH, J. N.; MITTAL, B.; NEWMAN, B. I. Comportamento do cliente: indo além do comportamento do consumidor. São Paulo: Atlas, 2001. 795 p.

SLONGO, L. A.; MÜSSNICH, R. Serviços ao Cliente e Marketing de Relacionamento no Setor Hoteleiro de Porto Alegre. Revista de Administração Contemporânea, Rio de Janeiro, v. 9, n. 1, p. 149-170, 2005.

ZEITHAML, V. A.; BITNER, M. J. Marketing de Serviços: a empresa com foco no cliente. Porto Alegre: Bookman, 2003. 536 p. 


\section{ANEXOS}

\section{Quadro 01: A Contraposição incluindo os artifícios para Fatores de Qualidade e} Aspectos Prejudiciais

\begin{tabular}{|c|c|}
\hline FATORES DE QUALIDADE & ASPECTOS PREJUDICIAIS \\
\hline $\begin{array}{l}\text { Rapidez na obtenção das informações e transações } \\
\text { dos serviços }\end{array}$ & $\begin{array}{l}\text { Demora para realizar as transações impedindo que a } \\
\text { operação se concretize. ( } \\
\text { congestioma sobrecarregado, } \\
\text { conento de linhas, conexão lenta) }\end{array}$ \\
\hline $\begin{array}{l}\text { Simplicidade no processo para efetuar operações, } \\
\text { serviço bem explicado. }\end{array}$ & $\begin{array}{l}\text { Sistema de operação com falta de informações e } \\
\text { instruções pouco claras. }\end{array}$ \\
\hline $\begin{array}{l}\text { Segurança e sigilo nas informações e transações } \\
\text { durante as operações bancárias. }\end{array}$ & $\begin{array}{l}\text { Falta de segurança por parte dos sistemas disponíveis } \\
\text { durante as transações. } \\
\text { (ação de hackers, clonagem) } \\
\text { Multiplicidade de senha para memorização }\end{array}$ \\
\hline $\begin{array}{l}\text { Possibilidade de acesso rápido às informações a } \\
\text { partir de qualquer lugar e horário }\end{array}$ & $\begin{array}{l}\text { Dificuldade de acesso ao site do banco pelo } \\
\text { computador. (fora do ar, falta de conexão) }\end{array}$ \\
\hline $\begin{array}{l}\text { Clareza e exatidão das informações } \\
\text { (serviço confiável) }\end{array}$ & $\begin{array}{c}\text { Informações incompletas e serviços realizados de forma } \\
\text { incorreta. (falta confiabilidade, erro no processo) }\end{array}$ \\
\hline $\begin{array}{c}\text { Possibilidade de realizar todas as informações e } \\
\text { transações que necessito. } \\
\text { (eficiente, eficaz) }\end{array}$ & Falta de Credibilidade \\
\hline $\begin{array}{l}\text { Disponibilizar todos os produtos do banco } \\
\text { (diversidade de operações) }\end{array}$ & Não disponibilizar todos os produtos do banco. \\
\hline Personalização & $\begin{array}{l}\text { Falta de personalização na prestação do serviço.(atenção } \\
\text { que o cliente deseja receber para resolver um problema) }\end{array}$ \\
\hline $\begin{array}{c}\text { Baixo custo das operações } \\
\text { (menos impostos, não pagar extratos) }\end{array}$ & $\begin{array}{c}\text { Despesas com a operação do serviço. } \\
\text { (cobranças de tarifas, conta telefônica alta) }\end{array}$ \\
\hline $\begin{array}{l}\text { Facilidade de manter-se atualizado(a) sobre } \\
\text { movimento bancário. (maior controle das contas ) }\end{array}$ & $\begin{array}{l}\text { Dificuldade de manter-se atualizado sobre movimento } \\
\text { bancário. }\end{array}$ \\
\hline Imagem do banco virtual & $\begin{array}{l}\text { Responsabilidade do banco é menor quando o } \\
\text { atendimento é on-line. (caso ocorra erro, o cliente pode } \\
\text { ficar no prejuízo). }\end{array}$ \\
\hline
\end{tabular}




\section{Quadro 02: Fatores de Qualidade Operacionalizados}

RAPIDEZ NAS TRANSAÇÕES: Obtenção rápida das informações e transações dos serviços, evitando demora para realização dos mesmos pelos clientes de forma que as operações pelo computador se concretizem.

ACESSO ÀS INFORMAÇÕES: Possibilidade de acesso rápido às informações a partir de qualquer lugar e horário, evitando dificuldades de acesso ao site do banco pelo computador.

SIMPLICIDADE NO PROCESSO: Poder efetuar operações de maneira simples e bem explicada, evitando falta de informações e instruções pouco claras no sistema de operação.

CLAREZA E EXATIDÃO: Obtenção de informações claras e exatas evitando que as mesmas estejam incompletas e que os serviços sejam realizados de forma incorreta.

SEGURANÇA NAS INFORMAÇÕES E TRANSAÇÕES: Sentir segurança nas informações e transações durante as operações bancárias pelo computador sem a interferência de terceiros, tendo garantia de sigilo através de senha de livre escolha.

REALIZAÇÃO DO SERVIÇO: Poder realizar todas as informações e transações com credibilidade.

OFERTA DE SERVIÇOS: Disponibilizar todos os produtos do banco.

PERSONALIZAÇÃO: Dar atenção que o cliente deseja para resolver um problema de forma personalizada.

CUSTO DAS OPERAÇÕES: Obter serviços a baixo custo.

FACILIDADE DE ATUALIZAÇÃO: Facilidade do cliente de manter-se atualizado(a) sobre as operações bancárias realizadas.

IMAGEM DO BANCO VIRTUAL: Responsabilidade maior com o cliente do banco, quando o atendimento é on-line. 


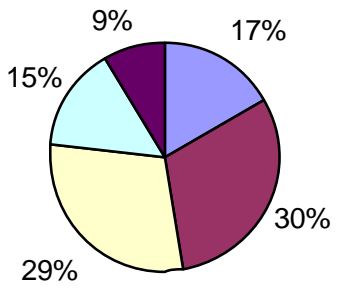

$\square$ até $R \$ 1.200,00$

$\square$ de $R \$ 1.201,00$ a $R \$ 2.400,00$

$\square$ de $R \$ 2.401,00$ a $R \$ 4.800,00$

$\square$ de $\mathrm{R} \$ 4.801,00$ a $\mathrm{R} \$ 7.200,00$

$\square$ mais de $\mathrm{R} \$ 7.200,00$

\section{Gráfico 01 - Distribuição de Freqüência da Renda dos Respondentes}

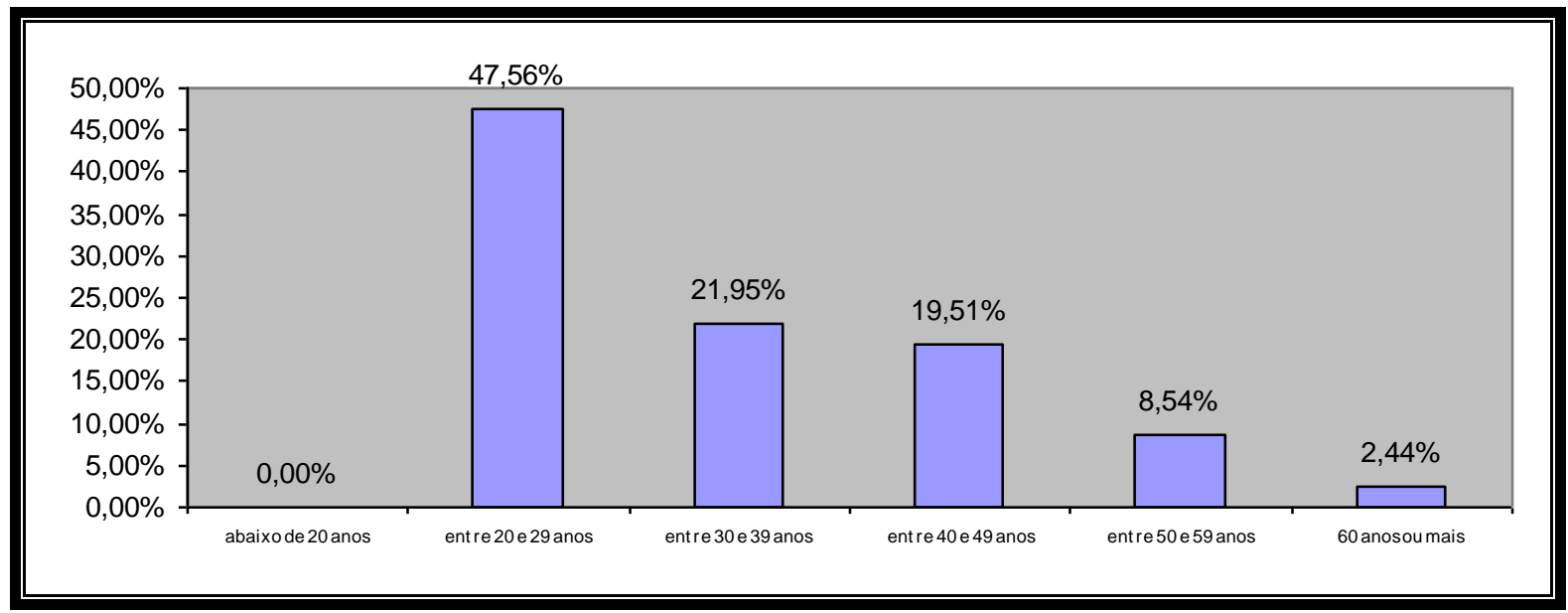

Gráfico 02 - Distribuição de Freqüência para Idade dos Respondentes

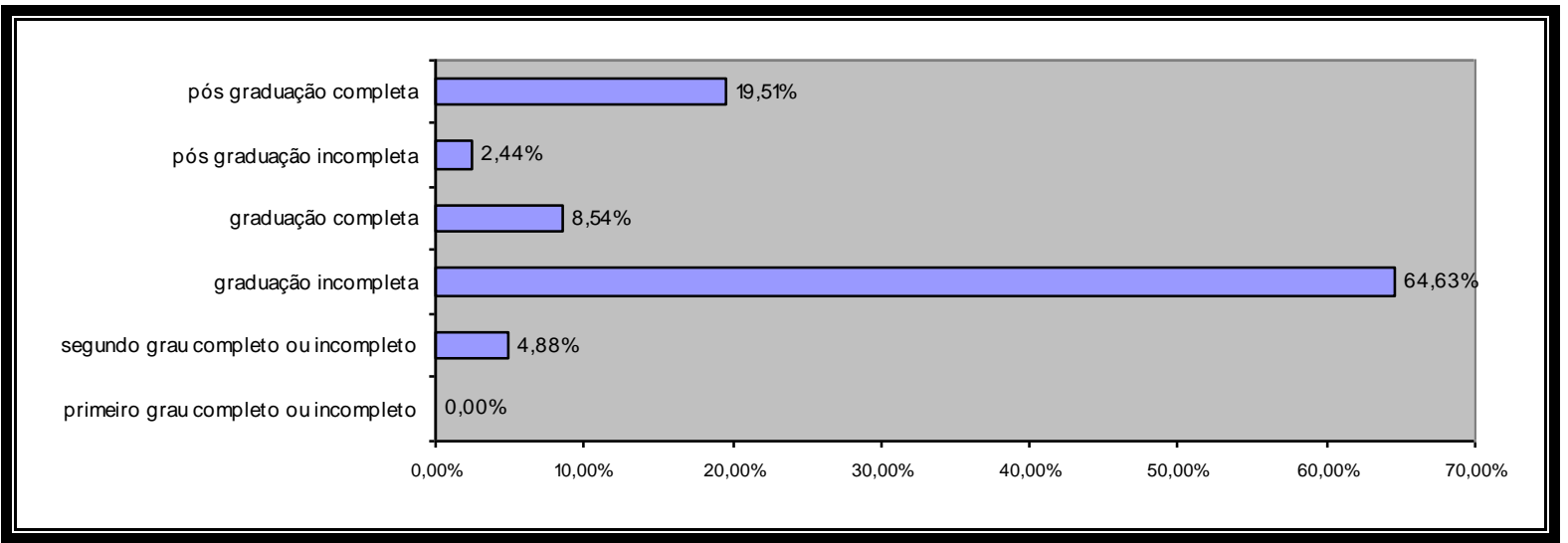

Gráfico 03 - Distribuição de Freqüência da Escolaridade dos Respondentes 
Quadro 03: Importância dos Fatores de Qualidade Operacionalizados

\begin{tabular}{|c|c|c|c|c|c|}
\hline POSTOS & $\begin{array}{c}\text { FATORES DE } \\
\text { QUALIDADE } \\
\text { OPERACIONALIZADOS }\end{array}$ & $\begin{array}{l}\text { FATORES DE } \\
\text { QUALIDADE }\end{array}$ & Média & $\begin{array}{l}\text { ASPECTOS } \\
\text { PREJUDICIAIS }\end{array}$ & Média \\
\hline 1 & $\begin{array}{l}\text { RAPIDEZ NAS } \\
\text { TRANSAÇÕES: }\end{array}$ & $\begin{array}{l}\text { (V1) Rapidez na } \\
\text { obtenção das } \\
\text { informações e } \\
\text { transaçôes dos } \\
\text { serviços }\end{array}$ & 4.30 & $\begin{array}{c}\text { (V23) Demora para } \\
\text { realizar as transações } \\
\text { impedindo que a operação } \\
\text { se concretize. }\end{array}$ & 4.98 \\
\hline 2 & $\begin{array}{l}\text { ACESSO ÀS } \\
\text { INFORMAÇÕES }\end{array}$ & $\begin{array}{l}\text { (V9) Possibilidade de } \\
\text { acesso rápido às } \\
\text { informações a partir } \\
\text { de qualquer lugar e } \\
\text { horário }\end{array}$ & 4.51 & $\begin{array}{l}\text { (V14) Dificuldade de } \\
\text { acesso ao site do banco } \\
\text { pelo computador. }\end{array}$ & 5.33 \\
\hline 3 & $\begin{array}{l}\text { REALIZAÇÃO DO } \\
\text { SERVIÇO }\end{array}$ & $\begin{array}{l}\text { (V3) Possibilidade de } \\
\text { realizar todas as } \\
\text { informações e } \\
\text { transaços que } \\
\text { necessito. }\end{array}$ & 5.26 & $\begin{array}{l}\text { (V15) Falta de } \\
\text { Credibilidade }\end{array}$ & 6.43 \\
\hline 4 & $\begin{array}{l}\text { SEGURANÇA NAS } \\
\text { INFORMAÇÕES E } \\
\text { TRANSAÇÕES }\end{array}$ & $\begin{array}{c}\text { (V7) Segurança e } \\
\text { sigilo nas informações } \\
\text { e transações durante as } \\
\text { operações bancárias. }\end{array}$ & 5.46 & $\begin{array}{l}\text { (V19) Falta de segurança } \\
\text { por parte dos sistemas } \\
\text { disponíveis durante as } \\
\text { transações. } \\
\text { (V13) Multiplicidade de } \\
\text { senha para memorizacão }\end{array}$ & 3.58 \\
\hline 5 & $\begin{array}{l}\text { CUSTO DAS } \\
\text { OPERAÇÕES }\end{array}$ & $\begin{array}{l}\text { (V5) Baixo custo das } \\
\text { operações }\end{array}$ & 5.84 & $\begin{array}{l}\text { (V18) Despesas com a } \\
\text { operação do serviço. }\end{array}$ & 6.97 \\
\hline 6 & $\begin{array}{l}\text { SIMPLICIDADE NO } \\
\text { PROCESSO }\end{array}$ & $\begin{array}{l}\text { (V2) Simplicidade no } \\
\text { processo para efetuar } \\
\text { operações, serviço } \\
\text { bem explicado. }\end{array}$ & 6.32 & $\begin{array}{l}\text { (V17) Sistema de operação } \\
\text { com falta de informaçes e } \\
\text { instruções pouco claras. }\end{array}$ & 6.12 \\
\hline 7 & $\begin{array}{l}\text { FACILIDADE DE } \\
\text { ATUALIZAÇÃOO }\end{array}$ & $\begin{array}{l}\text { (V11) Facilidade de } \\
\text { manter-se } \\
\text { atualizado(a) sobre } \\
\text { movimento bancário. }\end{array}$ & 6.59 & $\begin{array}{l}\text { Dificuldade de manter-se } \\
\text { atualizado sobre } \\
\text { movimento bancário. }\end{array}$ & \\
\hline 8 & CLAREZA E EXATIDÃO & $\begin{array}{l}\text { (V6) Clareza e } \\
\text { exatidão das } \\
\text { informações. }\end{array}$ & 6.76 & $\begin{array}{l}\text { (V22) Informações } \\
\text { incompletas e serviços } \\
\text { realizados de forma } \\
\text { incorreta. }\end{array}$ & 6.41 \\
\hline 9 & OFERTA DE SERVIÇOS & $\begin{array}{l}\text { (V4) Disponibilizar } \\
\text { todos os produtos do } \\
\text { banco. }\end{array}$ & 7.45 & $\begin{array}{l}\text { Não disponibilizar todos } \\
\text { os produtos do banco. }\end{array}$ & \\
\hline 10 & $\begin{array}{l}\text { IMAGEM DO BANCO } \\
\text { VIRTUAL }\end{array}$ & $\begin{array}{l}\text { (V12) Imagem do } \\
\text { banco virtual }\end{array}$ & 11.00 & $\begin{array}{l}\text { (V16)Responsabilidade do } \\
\text { banco é menor quando o } \\
\text { atendimento é on-line. }\end{array}$ & 5.55 \\
\hline 11 & PERSONALIZAÇÃO & Personalização & & $\begin{array}{c}\text { (V21) Falta de } \\
\text { personalização na } \\
\text { prestação do serviço. }\end{array}$ & 7.36 \\
\hline
\end{tabular}


Quadro 04 - Variáveis Relevantes na Identificação dos Grupos de Respondentes

\begin{tabular}{|c|c|c|c|c|}
\hline \multicolumn{3}{|c|}{ Fatores de Qualidade } & \multicolumn{2}{|c|}{ Aspectos Prejudiciais } \\
\hline & $\begin{array}{c}\text { Mais } \\
\text { Valorizados }\end{array}$ & $\begin{array}{c}\text { Menos } \\
\text { Valorizados }\end{array}$ & Mais Prejudiciais & Menos Prejudiciais \\
\hline 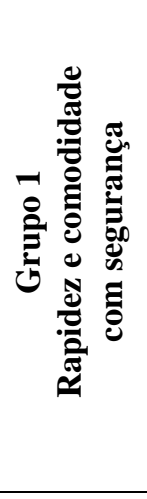 & $\begin{array}{c}\text { (V9)Possibilidade de } \\
\text { acesso rápido as } \\
\text { informações a partir de } \\
\text { qualquer lugar e horário } \\
\text { (V1)Rapidez na obtenção } \\
\text { das informações e } \\
\text { transações dos serviço. } \\
\text { (V10)O fato de não ser } \\
\text { necessário deslocar-se a } \\
\text { agência. }\end{array}$ & $\begin{array}{l}\text { (V12)Imagem do } \\
\text { banco virtual. } \\
\text { (V8)Impessoalidad } \\
\text { e }\end{array}$ & $\begin{array}{l}\text { (V19)Falta de } \\
\text { segurança por parte } \\
\text { dos sistemas } \\
\text { disponíveis durante } \\
\text { as transações. } \\
\text { (V20)Não permitir } \\
\text { depósitos. }\end{array}$ & $\begin{array}{l}\text { (V18)Despesa com as } \\
\text { operações do serviço. } \\
\text { (V15)Falta de } \\
\text { credibilidade. } \\
\text { (V21)Falta de } \\
\text { personalização na } \\
\text { prestação do serviço. }\end{array}$ \\
\hline 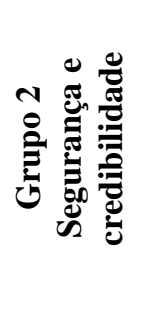 & $\begin{array}{l}\text { (V7) Segurança e sigilo } \\
\text { nas informações e } \\
\text { transações durante as } \\
\text { operações bancárias. }\end{array}$ & $\begin{array}{l}\text { (V12)Imagem do } \\
\text { banco virtual. } \\
\text { (V8)Impessoalidad } \\
\text { e }\end{array}$ & $\begin{array}{l}\text { (V19)Falta de } \\
\text { segurança por parte } \\
\text { dos sistemas } \\
\text { disponíveis durante } \\
\text { as transações. } \\
\\
\text { (V15)Falta de } \\
\text { credibilidade. }\end{array}$ & $\begin{array}{l}\text { (V20)Não permitir } \\
\text { depósitos. } \\
\text { (V21)Falta de } \\
\text { personalização na } \\
\text { prestação do serviço. }\end{array}$ \\
\hline 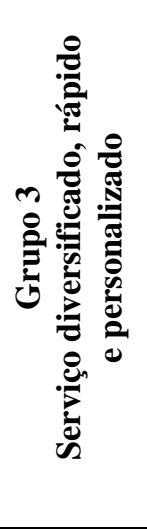 & $\begin{array}{l}\text { (V4)Disponibilizar todos } \\
\text { os produtos do banco. } \\
\text { (V3)Possibilidade de } \\
\text { realizar todas as } \\
\text { informações e transações } \\
\text { que necessita. } \\
\text { (V1)Rapidez na obtenção } \\
\text { das informações e } \\
\text { transações em serviço. }\end{array}$ & $\begin{array}{l}\text { (V11)Facilidade } \\
\text { de manter-se } \\
\text { atualizado sobre } \\
\text { movimento } \\
\text { bancário. } \\
\text { (V12)Imagem do } \\
\text { banco virtual. } \\
\text { (V10)O fato de } \\
\text { não ser necessário } \\
\text { deslocar-se a } \\
\text { agência. }\end{array}$ & $\begin{array}{l}\text { (V20)Não permitir } \\
\text { depósitos. } \\
\text { (V21)Falta de } \\
\text { personalização na } \\
\text { prestação do serviço. } \\
\text { (V23)Demora para } \\
\text { realizar as transações } \\
\text { impedindo que a } \\
\text { operação se } \\
\text { concretize. }\end{array}$ & $\begin{array}{l}\text { (V13)Multiplicidade de } \\
\text { senha para } \\
\text { memorização. } \\
\text { (V15)Falta de } \\
\text { credibilidade. } \\
\text { (V16)Responsabilidade } \\
\text { do banco é menor no } \\
\text { caso de erro quando o } \\
\text { atendimento é on-line. }\end{array}$ \\
\hline
\end{tabular}

